\title{
GCU
}

Glasgow Caledonian

University

University for the Common Good

\section{A novel in-line fibre-optic sensor for the detection of hydrate inhibitors within the oil and gas industry}

McDowell, G.R.; Uttamlal, M.; Holmes-Smith, A.S.; Graham, A.

Published in:

IEEE SENSORS, 2016

DOI:

10.1109/ICSENS.2016.7808603

Publication date:

2017

Document Version

Author accepted manuscript

Link to publication in ResearchOnline

Citation for published version (Harvard):

McDowell, GR, Uttamlal, M, Holmes-Smith, AS \& Graham, A 2017, A novel in-line fibre-optic sensor for the detection of hydrate inhibitors within the oil and gas industry. in IEEE SENSORS, 2016. IEEE, IEEE Sensors 2016, Orlando, United States, 30/10/16. https://doi.org/10.1109/ICSENS.2016.7808603

\section{General rights}

Copyright and moral rights for the publications made accessible in the public portal are retained by the authors and/or other copyright owners and it is a condition of accessing publications that users recognise and abide by the legal requirements associated with these rights.

Take down policy

If you believe that this document breaches copyright please view our takedown policy at https://edshare.gcu.ac.uk/id/eprint/5179 for details of how to contact us. 


\section{A Novel In-Line Fibre-Optic Sensor for the Detection of Hydrate Inhibitors within the Oil and Gas Industry}

\author{
G.R. McDowell, M. Uttamlal, A.S. Holmes-Smith* \\ School of Engineering \& Built Environment \\ Glasgow Caledonian University \\ Glasgow, G4 0BA, UK \\ a.s.smith@gcu.ac.uk
}

\author{
A. Graham \\ FMC Technologies \\ Bellshill, ML4 3PE, UK
}

\begin{abstract}
An in-line fibre-optic fluorescence-based sensing methodology for the detection of two common thermodynamic hydrate inhibitors (THI), monoethylene glycol (MEG) and methanol $(\mathrm{MeOH})$, used in the oil and gas industry has been developed. The fluorescence properties of two solvatochromic indicator probes were determined with varying ratios of THIs within oil-in-water mixtures. Sensor performance was evaluated for varying oil type, oil concentration and solution salinity to mimic the chemical composition of an oil flow line. Finally, an inline sensing capability was demonstrated using a purpose built industrial flow loop system with the results obtained showing that the concentration of known THIs can be determined to within $5 \%$ in the $0-50 \%$ THI concentration range. This measurement method has opened up the possibility of controlling hydrate inhibitor concentration in real-time, leading to improved flow assurance and substantial economic benefits.
\end{abstract}

Keywords-Chemical sensor, fluorescence, optical fibre, hydrate inhibitor, subsea applications

\section{INTRODUCTION}

The formation of gas (clathrate) hydrates, which are crystalline water based solids that resemble ice, within oil and gas pipelines causes major production problems within the industry. The first ever report of hydrate formation within natural gas pipelines was by Hammerschmidt in 1934 [1]. These hydrate particles agglomerate into hydrate plugs and stick to the wall of the pipeline, causing flow restriction and ultimately blockages [2]. The hydrates are formed when lighter alkanes such as methane combine with produced water, which readily occurs in subsea environments where the sea water outside the pipeline has a very low temperature $\left(4^{\circ} \mathrm{C}\right)$ and pressures are greater than 1,000 pounds per square inch (psi) [3]. It is imperative that these hydrate plugs are avoided, as they can cause pipeline blockages, reduce flow rate of oil and gas and hence affect oil recovery and profitability. The largest concern is safety, as hydrate formation in critical components within subsea infrastructure can cause them to stop functioning. For example, hydrate formation in safety valves can prevent valves closing, causing well blow-outs [4].

One method of preventing hydrate formation is to use thermodynamic hydrate inhibitors (THIs). The two most commonly used are monoethylene glycol (MEG) and methanol $(\mathrm{MeOH})$ [5]. Both are alcohols that suppress the freezing point of the water thus preventing hydrate formation
[6]. If hydrates form, the process is irreversible, therefore, operators pump tonnes of THIs continuously into their subsea infrastructures on a day-to-day basis to prevent hydrate formation, leading to one of the largest operating expenditures in the oil and gas sector. In 1994, Long et al. estimated that the cost of hydrate inhibition with methanol alone was in excess of $\$ 150$ million per year [7]. As of 2012, it was reported that up to 2,000 barrels of methanol is used per day depending on the location [8]. Although one of the cheapest inhibitors, the use of methanol is decreasing due to its toxicity and loss to the gas phase. Although more expensive, MEG is becoming the preferred inhibitor as it is easier to reclaim due to the invention of MEG reclamation units.

Currently, there is no fluorescence-based in-line technology that can detect the presence and concentration of MEG and/or $\mathrm{MeOH}$ within oil and gas pipelines [9]. Gas chromatography (GC) is often the method of choice for detecting low levels of $\mathrm{MeOH}$ topside [10], as regulations state that produced water (waste) from off-shore platforms must have less than 1,000 parts per million (ppm) of $\mathrm{MeOH}$ present. Other commercially available methods for THI determination use UV-Vis spectroscopy (OMMICA ${ }^{\mathrm{TM}}$, LUX Assure), electrical conductivity (HydraCHEK ${ }^{\circledR}$, Hydrafact) and NIR absorption spectroscopy (Red Eye MP ${ }^{\circledR}$, Weatherford). Many of these methods require sample preparation and/or are limited to detecting low THI concentration.

Here a new method based on the injection of a polarity sensitive fluorescence indicator into a pipeline and monitoring the peak wavelength of the fluorescence emission with changing THI concentration over the $0-50 \%$ range is presented. As the concentration of THI in the pipeline changes, then the polarity of the solution will change and this can be evaluated using spectroscopic techniques. The effect of changing oil type and concentration, salinity, temperature and pressure has also been investigated.

\section{EXPERIMENTAL METHODS}

Unless otherwise stated, all chemicals and reagents were purchased from commercial suppliers and used without any further purification. An ELGA PURELAB Option-R 7/15 purification system was used to dispense deionised water, with a $15 \mathrm{M} \Omega$ conductivity and this was used to prepare saline 
solutions $(0-10 \%)$ with commercially available Red Sea Salt used for marine fish tanks. Crude oil with American Petroleum Institute (API) gravity values of 21, 31 and 35 were used as supplied by FMC Technologies. Oil-in-water emulsions were prepared by using a probe sonicator (MPI Ultrasonics Sonotrode) with power output of $1000 \mathrm{~W}$ at 20.4 $\mathrm{kHz}$ for 4 minutes. Samples were re-sonicated for 1 minute prior to analysis.

Calibration was carried out using a custom built bench top instrument which employed either a $532 \mathrm{~nm}$ or $638 \mathrm{~nm}$ laser diode from LaserBOXX as the excitation source. A bifurcated fibre optic (FCR-7IR-400-2-ME, Avantes Engineering), consisting of seven $400 \mu \mathrm{m}$ fibres was employed as a light conduit with the six fibres round the perimeter transporting the excitation light and the central fibre collecting the fluorescence emission. Fluorescence spectra were recorded using a Hammamatsu C10082CA TM series minispectrometer.

To demonstrate the feasibility of the method the bench top instrument was incorporated into a custom built flow loop which had a maximum capacity of 10.8 litres of water. The water based solutions were circulated at a desired flow rate using an EBARA DWO 20010 bar flow pump and controlled using a SIMEX Multichannel Controller (MultiCon) CMC-99 data logger. The flow rate was monitored using an Endress and Hauser Proline Promag 50 W Flowmeter. Varying pressure was achieved using the pressure valve connected to a Virax 26203550 bar 5 litre test pump and monitored using an Endress and Hauser Ceraphant T PTC31 pressure sensor. Temperature was recorded by 4 Type $\mathrm{K}$ thermocouples, fixed to various sections of pipe and a fifth thermocouple was disconnected from the flow loop and monitored the temperature of the lab as a control. The bifurcated fibre-optic reflection probe was fixed into position at a glass window to allow light into and out of the flow loop.

In the flow loop configuration $2.2-3.3 \mathrm{ml}$ of a $1 \times 10^{-2} \mathrm{M}$ stock solution of the fluorescent indicator was injected into the flow line. The resulting concentration of the indicator in the flow loop was then between 2 and $3 \mu \mathrm{M}$ giving $0.02-0.03 \%$ $\mathrm{w} / \mathrm{v}$ of dye injected. Fluorescence peak wavelengths and intensities stabilised 150-180 seconds after injection.

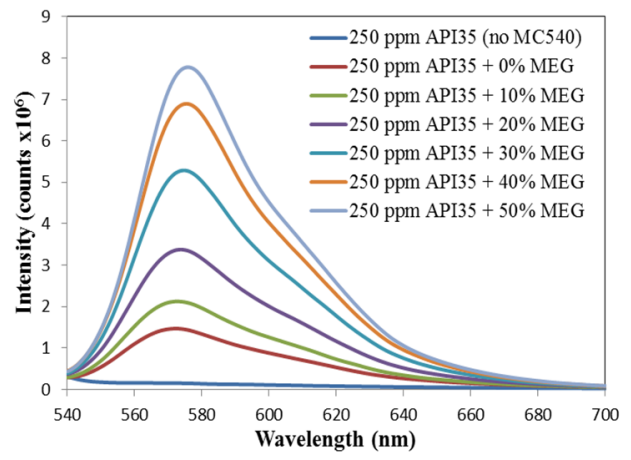

Fig. 1. Fluorescence spectra of $250 \mathrm{ppm}$ crude oil (API35) in 3.5\% saline solution and $3 \mu \mathrm{M}$ MC540 in the same crude oil with increasing MEG concentration, $\lambda_{\mathrm{ex}}=532 \mathrm{~nm}$.

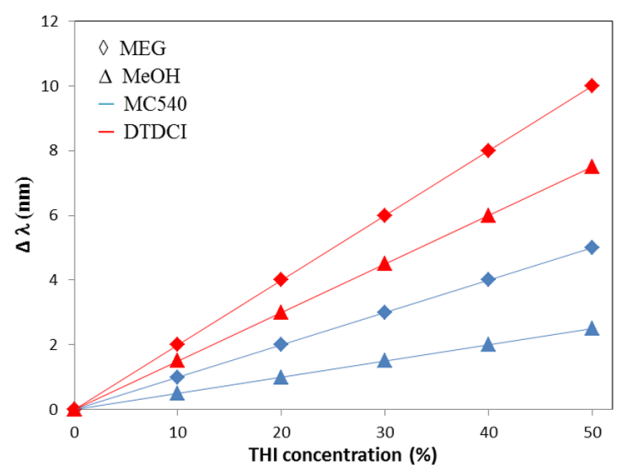

Fig. 2. Calibration graphs for $3 \mu \mathrm{M}$ of fluorescent dye with changing THI concentration: MC540, $\lambda_{\mathrm{ex}}=532 \mathrm{~nm}$, DTDCI, $\lambda_{\mathrm{ex}}=638 \mathrm{~nm}$. $\Delta \lambda$ is the shift in fluorescence peak wavelength from that observed in saline solution.

\section{RESULTS AND DISCUSSION}

\section{A. Solvatochromic Dyes}

Crude oil, which contains aromatic hydrocarbons, is highly fluorescent when excited by UV or blue light. Hence, when identifying a suitable fluorescent polarity sensitive dye, one of the main criteria was that the excitation light should have a wavelength greater than $500 \mathrm{~nm}$ to minimise excitation of the aromatic hydrocarbons in the crude oil. Two suitable fluorescent cyanine based solvatochromic dyes were identified, Merocyanine 540 (MC540) and 3,3'diethylthidicarbocyanine iodide (DTDCI) which have peak absorbance wavelength at $533 \mathrm{~nm}$ and $645 \mathrm{~nm}$ in water respectively. The emission spectrum of API35 crude oil in $3.5 \%$ saline solution, when excited at a wavelength of $532 \mathrm{~nm}$, is negligible in comparison to the fluorescence of the solvatochromic probe as shown in Fig. 1. For DTDCI, where $\lambda_{\mathrm{ex}}=638 \mathrm{~nm}$, the fluorescence of the crude oil is further diminished by 2 -fold. Hence both of these indicator molecules have demonstarted their suitablity for application within a real-time oil flow line environment as no spectral subtraction or manipulation is required as oil fluorescence is minimal.

Fig. 1 also shows the emission spectra of MC540 in varying concentrations of MEG. As the concentration of MEG increases the fluorescence intensity of the MC540 emission increases with a clear red shift of the peak emission wavelength. The fluorescence intensity increases due to the quantum yield of MC540 increasing. Additionally, the fluorescence peak wavelength of MC540 shifts to longer wavelengths due to the polarity of the solution decreasing (negative solvatochromism). Hence, by monitoring the peak emission wavelength, a sensor for THI can be implemented which is independent of the concentration of the cyanine dye present.

Calibration curves obtained for both dyes in the $0-50 \%$ THI range are presented in Fig. 2 with a summary of the sensitivities and uncertainties given in Table 1 . In order to assess the effect of varying the oil concentration in the $0-500$ ppm range, oil type and solution salinity $(0-10 \%)$, repeated measurements were performed and the peak emission wavelength values from all these variations averaged and standard deviation determined. The column in Table 1 reporting the $\lambda$ variation gives the $95 \%$ confidence interval for 
these measurements. From this the largest expected error for THI concentration recovered for varying chemical compositions in the pipeline can be estimated and this is also given in Table 1. Results show that the highest uncertainties in THI determination are all less than $\pm 5.3 \%$, which is within acceptable limits for a real time THI monitor within a pipeline.

\section{B. Flow Loop}

In order to demonstrate the practical application of the sensor, the fluorescence indicators were injected into a purpose built flow loop and the concentration of THI varied. Circulating liquid round the flow loop at a desired flow rate results in a temperature rise which can be monitored using the thermocouples attached at strategic locations round the loop. In addition, the pressure within the loop can also be controlled.

The effect of temperature and pressure on the fluorescence properties of the indicator dyes were determined by changing either the flow rate and/or the pressure within the loop. By keeping the flow rate $\left(3 \mathrm{~ms}^{-1}\right)$ consistently high, the temperature is shown to rise, whereas the pressure only shows a minor increase. Over the $14{ }^{\circ} \mathrm{C}$ temperature increase the fluorescence peak wavelength of MC540 shows a change of $+0.04 \mathrm{~nm} /{ }^{\circ} \mathrm{C}$ and was reversible upon cool down of the flow loop. Given that temperature is continuously monitored within subsea pipelines and processing plants, correction to the measured peak wavelength can be easily achieved. Fig. 3 shows how the fluorescence peak wavelength response of 2 $\mu \mathrm{M}$ MC540 (in water) varies with pressure within the flow loop, where no significant variation is observed $(572.96 \pm 0.06$ $\mathrm{nm}, \mathrm{RSD}=0.01 \%$ ). In the case of DTDCI variations in both temperature and pressure caused the peak emission wavelength to vary by $<0.13 \mathrm{~nm}$, i.e. within the resolution of the spectrometer, hence no correction is necessary in this case.

THIs were then injected into the flow loop and the calibration graphs in Fig. 2 were used to determine the concentration of THI in the flow loop and compared to the known concentration added. The differences between the recovered THI concentration and that added to the flow loop for both dyes were all less than 5\% demonstrating that the methodology described here can determine THI concentration within the target value.

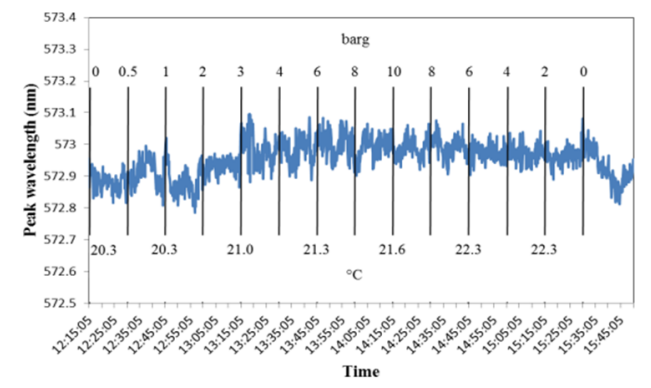

Fig. 3. Fluorescence peak wavelength response of $2 \mu \mathrm{M}$ MC540 in water with pressure within the flow loop.
TABLE I. FLUORESCENCE PEAK WAVELENGTH SENSITIVITY VALUES FOR $2 \mu \mathrm{M}$ MC540 AND $3 \mu \mathrm{M}$ DTDCI IN A 250 PPM CRUDE OIL 3.5\% SALINE SOLUTION, LARGEST PEAK WAVELENGTH VARIATION OVER ALL SOLUTION CONDITIONS (SEE TEXT) AND RESULTING UNCERTAINTY IN THI\%.

\begin{tabular}{|c|c|c|c|c|}
\hline $\begin{array}{l}\text { Fluorescence } \\
\text { Indicator }\end{array}$ & THI & $\begin{array}{c}\lambda \text { shift } \\
\text { sensitivity } \\
(n m / \% H I)\end{array}$ & $\begin{array}{c}\lambda \text { variation } \\
( \pm \mathrm{nm} @ \\
\mathrm{THI} \%)\end{array}$ & $\begin{array}{l}\text { THI conc. } \\
\text { uncertainty } \\
( \pm \%)\end{array}$ \\
\hline \multirow[t]{2}{*}{ MC540 } & MEG & $\begin{array}{c}+0.101 \pm \\
0.002\end{array}$ & 0.27 at $10 \%$ & 2.7 \\
\hline & $\mathrm{MeOH}$ & $\begin{array}{c}+0.053 \pm \\
0.002\end{array}$ & 0.28 at $50 \%$ & 5.3 \\
\hline \multirow[t]{2}{*}{ DTDCI } & MEG & $\begin{array}{c}+0.177 \pm \\
0.012\end{array}$ & 0.49 at $20 \%$ & 2.8 \\
\hline & $\mathrm{MeOH}$ & $\begin{array}{c}+0.102 \pm \\
0.006\end{array}$ & 0.43 at $10 \%$ & 4.2 \\
\hline
\end{tabular}

\section{CONCLUSIONS}

The use of the negative solvatochromic fluorescent probes, MC540 and DTDCI, for THI determination in an in-line sensing configuration within a flow loop has been demonstrated where the THI concentration can be determined to within $5 \%$ of the actual value. For both dyes the sensitivity to $\mathrm{MEG}$ was greater than $\mathrm{MeOH}$ and the more sensitive dye was found to be DTDCI which showed no sensitivity to temperature and pressure. The results presented demonstrate the feasibility of this method for deployment in oil and gas pipelines.

\section{REFERENCES}

[1] E. G. Hammerschmidt, "Formation of gas hydrates in natural gas transmission lines," Ind. Eng. Chem., vol. 26, pp. 851-855, 1934.

[2] E. D. Sloan, C. Koh, and A. K. Sum, Natural Gas Hydrate in Flow Assurance. Massachussetts: Gulf Professional Publishing, 2011.

[3] S. Gao, "Investigation of Interactions between Gas Hydrates and Several Other Flow Assurance Elements," Energy \& Fuels, vol. 22, no. 6, pp. 3150-3153, 2008.

[4] D. M. Faichnie, A. Graham, L. Costello, and D. McStay, "Use of fibre sensors for temperature measurement in subsea infrastructure to monitor flow-loop cool-down," J. Phys. Conf. Ser., vol. 178, p. (012018) 1-6, Jul. 2009.

[5] D. L. Katz and R. L. Lee, Natural Gas Engineering: Production and Storage. New York: McGraw-Hill, 1990.

[6] M. Riaz, G. M. Kontogeorgis, E. H. Stenby, W. Yan, T. Haugum, K. O. Christensen, E. Solbraa, and T. V. Løkken, "Mutual solubility of MEG, water and reservoir fluid: Experimental measurements and modeling using the CPA equation of state," Fluid Phase Equilib., vol. 300, no. 12, pp. 172-181, Jan. 2011.

[7] J. Long, J. Lederhos, A. Sum, R. L. Christiansen, and E. D. Sloan, "Kinetic inhibitors of Natural Gas Hydrates," in Proceedings of the 73rd Annual GPA Convention, 1994.

[8] “Gibson Applied Technology and Engineering (GATE) Inc - Hydrates: Prediction, Mitigation \& Remediation Techniques." 2012.

[9] "Gibson Applied Technology and Engineering (GATE) Inc - Methanol in Produced Water Discharge." 2012.

[10] “ATSM D7059 - Standard Test Method for Determination of Method in Crude Oils by Multidimensional Gas Chromatography." [Online]. Available: http://www.astm.org/Standards/D7059. [Accessed: 31-May2016]. 